\title{
ЗАГАДОЧНЫЙ ЭПИР: СТРАНА СВЯТИЛИЩ И ОРАКУЛОВ
}

Статья посвящена святилищам и оракулам античного Эпира, области, находившейся на Севере Греции и считавшейся самой загадочной и таинственной в стране. Сам Эпир являлся самой дальней северной точкой древнегреческой цивилизации. По мнению автора, отдаленность Эпира от культурных центров Греции привела к отсутствию знаний греков об этом регионе и даже к обвинению эпиротов в варварстве. Сама же топография региона отличалась удивительным разнообразием, включая в себя высокие горные хребты, болотистые лагуны, непроходимые ущелья, высокогорные плато, бурные горные реки. Именно здесь возникли многочисленные святилища, оракулы и другие священные места, самым известным из которых является оракул Зевса в Додоне. Автор впервые в историографии ставить вопрос о взаимосвязи природных условий региона с возникновением здесь различных культовых мест - святилищ, оракулов, храмов и т.д. Широко известны были не только в самом регионе, но во всей Древней Греции Додонский оракул, святилище Зекса в Пассароне, оракул мертвых на Ахеронте, Нимфей в Аполлонии, святилище Асклепия в Буфроте и т.д. Но наиболее известным из них являлся Додонский оракул, который долгое время был единственной ниточкой, связывающей Эпир со всеми остальными районами Греции. Несмотря на труднодоступность, в Эпир стремились путешественники со всей Греции. Священный дуб, бьющий из-под земли волшебный родник, обитающие на дубе священные голуби, медные котлы - все они служили средствами прорицания, посредством которых верховный бог Зевс вещал вопрошающим свою волю. Все находящиеся здесь святилища ещё требуют дальнейших исследований.

Ключевые слова: Эпир, Северная Греция, периферия, ландшафт, святилище, оракул.

\section{MYSTERIOUS EPIRUS: COUNTRY OF SANCTUARIES AND ORACLES}

The article is devoted to the sanctuaries and oracles of ancient Epirus, a region located in the north of Greece and considered the most mysterious in the country. Epirus itself was the farthest northern point of ancient Greek civilization. According to the author, the remoteness of Epirus from the cultural centers of Greece led to the lack of knowledge of the Greeks about this region and even to the accusation of epirots of barbarism. The very topography of the region was remarkable for its amazing diversity, including high mountain ranges, marshy lagoons, impassable gorges, high-altitude plateaus, turbulent mountain rivers. It was here that numerous shrines, oracles and other sacred sites arose, the most famous of which is the oracle of Zeus in Dodona. The author for the first time in historiography raised the question of the relationship of the natural conditions of the region with the emergence of various religious places - sanctuaries, ora-

На севере Древней Греции, на самой границе, отделяющей греческую цивилизацию от варварского мира, находилась область, получившая название Эпир. Его территория располагалась к северу от Амбракийского залива, к востоку - от Фессалии, на западе же её естественной границей служило побережье Ионийского моря [8, s. 276]. Но наиболее четкая его граница пролегала на севере, где Керавнские горы отделяли Эпир от соседней Иллирии [10, s. 85]. Само название области «Эпир» и жителей «эпироты» не являлось самоназванием и в переводе с греческого означало соответственно «суша» и «жите- cles, temples, etc. The Dodon oracle, the sanctuary of Zeus in Passaron, the oracle of the dead on Acheron, Nymphaeum in Apollonia, the sanctuary of Asclepius in Buthrotum etc., were widely known not only in the region itself, but in the whole of ancient Greece. However, the most famous of them was the Dodonean oracle, which for a long time was the only thread connecting Epirus with all the rest of Greece. Despite the inaccessibility, pilgrims from all over Greece sought to Epirus. The sacred oak, a magical spring spouting out of the ground, sacred pigeons living on an oak tree, copper cauldrons - they all served as means of divination by which the supreme god Zeus spoke to those who asked him his will. All the sanctuaries here still require further research.

Key words: Epirus, Northern Greece, periphery, landscape, sanctuary, oracles.

ли суши». Однако с течением времени это сугубо географическое название постепенно приобрело политическое значение.

Территория Эпира делилась на три области: Северный, Центральный и Южный Эпир. Северный Эпир, ареал обитания таких племен, как хаоны, атинтаны и паравеи, ныне располагается на территории современной Албании, в то время как Центральный и Южный Эпир являвшийся территорией проживания молоссов (вокруг озера Янины), феспротов (по побережью рек Фиамиса и Ахеронта) и кассопов (юго-западная часть Эпира), и ныне находится на севере самой Греции. 
На востоке области горы Пинда образовали естественную границу, многочисленные цепи которого тянутся через всю Северную и Центральную Грецию с севера на юг. Труднопроходимые высокогорные тропы (на высоте 1700 м.) все же делали возможными контакты между Эпиром и соседней Фессалией

Оговоримся сразу: основной целью нашей статьи отнюдь не является рассмотрение топографии древнего Эпира - в свое время это было сделано немецким ученым Г. Трайдлером, в его давно изданной, но отнюдь не устаревшей на сегодняшний день монографии [10]. Наша цель намного скромнее: нащупать связь между природными условиями региона и возникшими здесь с самых древних времен многочисленными святилищами

С давних пор территория Эпира в глазах жителей Эллады обрела ореол загадочности, таинственности и даже некой мистичности. Но перед тем, как рассматривать природные условия региона, кратко коснемся самих его обитателей. В течение длительного времени жители Средней и Южной Греции, плохо знавшие своих северных соседей, считали их варварами. Так, известный древнегреческий историк Фукидид, перечисляя участников похода спартанца Кнема в 429 г. до н.э., употребляет фразу «хаоны и другие варвары», по-видимому, подразумевая под «другими варварами» проживающие также на территории Эпира племена молоссов, феспротов, атентан, паравеев и орестов. Но называя своих северных соседей варварами, едва ли греки имели в виду их этническую принадлежность. Несмотря на то, что проблема этнической принадлежности эпиротов все ещё далека от своего окончательного разрешения, рискнем предположить, что в этом пассаже речь идет совсем о другом. Как известно, "обвинение в варварстве» со стороны эллинов могли заслужить те народы, которые отличались от них по образу жизни, культуре и языку. Посмотрев на эпиротов с позиции афинского историка классической эпохи, мы можем с большей долей вероятности определить, что он имел в виду, называя эпиротов варварами. Располагавшийся на периферии греческого мира Эпир по причине своей удаленности от культурных центров Эллады, был вынужден соприкасаться с действительно варварским миром (в основном - с иллирийским), что не могло не наложить отпечатка на их характер и обычаи. «Эпироты, удаленные от центра греческой культуры, влачили свое жалкое существование», - отмечал немецкий исследователь Г. Шмидт [9, s. 17]. Они не принимали никакого участия в общегреческих делах, начиная от Троянской войны и до греко-персидских войн. Географическая удаленность и длительное соприкосновение с варварским миром тормозили их культурное развитие. Однако, по мнению Н. Хэммонда, упомянутое выше высказывание Фукидида никак не может служить критерием для определения этнического происхождения эпиротов [5, p. 422]. Но если западные ученые обраща- ли внимание на «культурную» и «политическую» отсталость, то советские ученые предпочитали говорить об отсталости «экономической», что наиболее четко это проявилось в той характеристике, которую дала северным областям Древней Греции отечественная исследовательница Р. В. Шмидт: «В таких областях, как Эпир, Фессалия, Македония и др., обладавших благоприятными естественными условиями для земледелия и скотоводства, дольше сохранялись элементы родового строя; эти области были в гораздо меньшей степени захвачены товарно-денежными отношениями, они стояли в стороне от торговых путей. Основную и господствующую отрасль производства в этих областях представляло земледелие и отчасти скотоводство, поэтому сельские интересы преобладали над городскими» [1, с. 206].

Но загадочность Эпира и его обитателей была напрямую связана с его древностью. Не случайно Аристотель называл территорию Додоны и прилегающей к ней долины колыбелью греков. Ссылка на Аристотеля дополняется археологическими данными. Эпир, особенно в его южной части, содержит в себе материальные свидетельства практически всех предшествующих доисторических эпох. Именно здесь впервые в Греции были обнаружены обтесанные каменные блоки эпохи палеолита [6, p. 2]

Природные ландшафты местности, действительно, отличались поразительным разнообразием. Здесь встречались морское побережье и горные вершины, соединенные узкими горными проходами, болотистые лагуны и ровные, плоские долины [6, р. 2]

И жители данного региона действительно оправдывали то мнение, которое сложилось о них среди жителей остальной части Греции. Выразилось это в возникновении с самых древних пор различного рода святилищ и оракулов, использующих самые разные средства прорицания.

Какие же святилища и оракулы Эпира нам известны? Исследователи среди них выделяют оракул мертвых на Ахеронте, святилище Зевса в Пассароне, святилище Асклепия в Буфроте, Нимфрейон (святилище Нимф) в Аполлонии, святилище Аполлона в Никополе [7, s. 158, 164, 172, 179 187]. Однако наиболее известным из них все-таки является святилище Зевса в Додоне с одноименным оракулом.

Остановимся на некоторых топографических особенностях местоположения Додонского святилища, поскольку описания его нам хорошо известны.

Античными авторами Додонский оракул единодушно считался древнейшим святилищем Древней Греции. Однако удивительно то, что ни один из этих авторов ни единым словом не упомянул о труднодоступности данного региона. А он имел свои особенности, на которые мы считаем возможным обратить свое внимание. Как справедливо предположил один из современных исследователей, количество визитеров в Додоне никогда не было чрезмерным как из-за качества дорог, так 
и из-за их удаленности [4, р. 97]. Другой современный автор, Тревор Курнов, также выражает искренне удивление стремлением посетителей достичь этого труднодоступного места, которое и сегодня недоступно для воздушного сообщения и очень слабо соединено с Яниной общественным транспортом [2, р. 60].

Точно идентифицированная исследователями XIX в. территория Додонского оракула располагалась к юго-западу от Янины, (примерно в 22 км) небольшого современного города на северо-западе Греции. Додона лежала на пути от побережья Феспротии в долину Фиамис. Сегодня попасть в Додону можно только по единственной высокогорной ответвленной дороге, минуя около десяти миль к югу от Янины. Здесь находится длинная узкая высокогорная долина, расположенная примерно в 600 м над уровнем моря, которая большую часть дня затемнено почти отвесной скалой Томар (современная Олитцка)

На востоке Додонское святилище отделено от равнины Янины цепью гор из мелового камня. Гора Томар тянется в высоту на 6.500 футов и «подпирается» цепью крутых горных вершин. На её склонах разбросаны узкие ущелья. Стремительные потоки, питаемые тающими снегами, стекают с вершин. Снег на верхних склонах лежит более четырех месяцев в году. У подножья горы в северо-западном направлении расположена узкая долина, длинной 12 км и 1200 м шириной в самом широком месте.

Климат региона весьма суровый и здесь нельзя не вспомнить характеристику Гомера, назвавшего Додону «суровой своими зимами». Долину часто заливают яростные грозы, которые несут стремительные дождевые потоки, наполняя летом горные водопады и делая почву необыкновенно болотистой. Но долина заболочена не только частыми осадками, но и многочисленными источниками, которые прячет в себе гора Томар

Предгорья горы Томар покрыты сосновыми деревьями, в то время, как внизу на равнине растут несколько дубов. Протекающие здесь реки Ахерон и Коцит, согласно мифологической традиции связаны с внешним миром. Недалеко от них протекает ещё одна река - Ахелоос, которая спускается к Акарнании. А около 3 км к югу от святилища находятся истоки Лура.

Основной маршрут, которым паломники попадали в Додону, вероятно, находился на юге, параллельно современной Талахсе.

Все это свидетельствует о том, что Додона находилась в весьма труднодоступном для паломников месте и им приходилось преодолевать немалые усилия и трудности, чтобы её достичь. И судя по всему, эти трудности их не останавливали.

Интересный пассаж на этот счет оставил выдающийся исследователь Додонского оракула, греческий археолог Сотириос Дакарис: «Возможный посетитель, прибывающий в Бриндизи, высаживается в Игуменитцах. После перехода через живописную долину р. Каламос отсюда он попадает на дорогу Арта - Афины, и минуя холмы Николайос-Манолисса, через 30 минут достигает искомого места» [3, р. 2]. При этом надо учитывать один нюанс: С. Дакарис имел в виду не древнего, а современного путешественника, которому преодоление трудностей, учитывая современные средства коммуникаций, будет даваться гораздо легче.

По нашему мнению, именно труднодоступность расположения святилища была одной причин бытовавшего среди греков мнения о его древности, загадочности и таинственности.

Чтобы определить местонахождение Додоны было неразрывно связано с обнаружением остатков старинного оракула. Однако месторасположение этого святилища, признанного в античном мире, долгое время не могли обнаружить. Цари, полководцы, важные государственные чиновники, - они все приходили к нему консультироваться о своем будущем и будущем Греции, шли со всех сторон: со стороны Амфиполя на востоке, от Аполлонии на западе, с берегов Азии и Италии [11, p. 247]. Эти походы сопровождались таким количеством трудностей, что их участники должны были действительно верить его предсказаниям. Но мы не можем думать о бесполезности этих консультаций в Додоне. Что-то должно было там быть особенное. Руины великой столицы отличались от руин нижнего города, а те в свою очередь от руин крепости; однако руины религиозного города должны быть отличны от выше перечисленных руин. Что, по нашему мнению, особо усложняет постановку вопроса, не только малое количество информации, но и ее противоречивость. Существует столько условий, которые надо соблюсти, чтобы определить местонахождение Додоны, что это кажется мало реальным.

Озеро, высокая гора, сотня источников, чудесный фонтан, искрящийся светом, дубовый лес, открытая и просторная долина, отличные пастбища, - вот эти отличительные черты [11, р. 248]. Все это выглядело весьма живописно и не могло не впечатлять прибывших сюда паломников. Вот как описала в 1908 г. путешествие Додону сопровождавшая своего супруга, немецкого археолога Теодоро Виганда (1864-1936) его жена Марта, урожденная Сименс: «На следующее утро мы на лошадях отправились в Додону. Мы ехали 4 часа, сначала быстро через ровную лужайку, а затем по крутой каменной высокогорной дороге. Там среди древних дубов находилось здание додонского святилища, небольшая капелла и отсюда мы увидели открывшиеся нашему взору небольшое село и заснеженные вершины горы Томар... Пока сам Т. Виганд фоотографировал и делал обмеры, его супруга восхищалась окружающим ландшафтом [11, s. 44]. Многие современные исследователи пытаются наложить все эти черты на какое-нибудь из сохранившихся до наших времен мест, но найти подобные аналоги неимоверно сложно. Рассматривая Додону только как город, а не как местность, можно заметить, что это место было самым живописным в этом регионе и единственным в своем роде на многие мили вокруг. Больше нельзя отрицать ту важность, которую придавало ему его священное отличительное свойство. Теперь предположим, что странник, оказавшийся 
В этой части Греции, встречал фосфорический источник, в котором зажигалась воспламеняемая субстанция; если его спрашивали по его возвращению, где он видел этот источник, скорее всего он отвечал, что видел его где-то рядом с Додоной. Вот таким образом вокруг этого места и появлялось то божественное свойство. По нашему мнению, Додона - это не только город, а, скорее, местность. Мы это видим главным образом в том, что чтобы объединить в себе все вышеперечисленные особенности, необходимо иметь более значительные площади, чем священный ансамбль пророческого храма.

Так как некоторые авторы размещали Додону в Молоссии, а другие в Феспротии, можно сделать вывод, что она находилась на границе этих двух стран. Но и это утверждение весьма сомнительно. В давно минувшие времена, Додона находилась в Феспротии, а позже в Молоссии. На самом деле самая большая часть Феспротии была захвачена молоссами. Теперь что касается самых важных данных об определение нахождения Додоны: речь идет о расстоянии в четыре дня ходьбы от Буфррота по устью реки Дельвино (Delvino) и о расстоянии в два дня пути от Амбракии до современной Арты (Arta) [12, p. 249]. Важно помнить, что в этой последней дистанции спускаются с горных цепей, простирающихся с севера на юг, между Пиндом и Ионийским морем, в то время как в первой дистанции на них поднимаются. Все эти утверждения обретают свой вес при виде античного города, руины которого заслуживают внимание. Когда путешественники направляются к ним, они проходят от Янины к юго-западу и через час добираются до деревни Граписта (Grapista) слева и горного прохода справа, затем оставляют за собой слева церковь Эклессия Бодиста (Ecclesia Bodista), и, в конце концов, спускаются обширную долину, простирающуюся под восточными хребтами горы Олица (Olitza). Руины, расположенные посреди этой долины находятся порядка в 11 милях к юго-западу от Янины. Эти руины называют Кастро (Kastro), второе название - древняя цитадель Драмис (Dramisus). Первое, что поражает зрителя, созерцающего эти руины, это их расположение. Они расположены на равнине. Выбор такого месторасположения свидетельствует об огромной уверенности жителей в ресурсах их города; как известно, основным принципом расположения древнегреческих городов-полисов, это расположение их цитадели на горе. Древнегреческий город всегда ожидал нападения из вне. Руины, которыми нами рассмотрены, являются неоспоримо греческими, хотя они и расположены на равнине посреди одной из самых горных областей Греции. В этом регионе не хватало населенных пунктов, со всех сторон возвышались горы, которые, даже казалось, оспаривали право древнегреческого города украшать своими стенами их гордые вершины. Таким образом, выбор размещения в долине должен был быть сделан для чего-то особенного. Эта особенность становится еще более отличительной, если рассматривать незначительные размеры города. Сила его населения никогда бы не компенсировала слабости его позиции. Периметр его стен не превышает двух английских миль. Рассмотрение этих фактов, то есть расположение в равнине и малая протяженность, кажутся решающими возражениями против мнения, согласно которому эти руинь относят к Пассарону, другому культовому центру Эпира [12, р. 252]

Но перед тем как согласовать наше описание с описанием из древних времен нужно, чтобы другие черты Додоны собрались воедино, чтобы все это пришло в соответствие с древней традиции. Чтобы найти озеро Додоны, нам необходимо перенестись в Янину, расположенную в восьми милях. Фосорорический источник, возможно, мог, находится рядом с шахтами, прорытыми Али-пашой (Ali Pacha) в Джеровини (Djerovini); гора Томар (Tomarus) может быть представлена как Олецка (Oletzka) c ее сотнями фонтанов и плодородной долиной в низине. Другой след этого оракула также заслуживает нашего внимания. Древняя традиция повествует о епископе Додоны, существовавшем еще в пятом веке, а новое имя, данное этому месту в имперских рескриптах той эпохи Бондица (Bonditza).

Таким образом, перед нами описание природных условий одного из святилищ Эпира, самого известного, но оно дает нам представление о той причудливой и живописной, но одновременно таинственной и загадочной местности, которая служила территорией размещения более, чем десятка различных святилищ и оракулов.

\section{Источники и литература / References}

1. Шмидт Р. Спарта. Беотия. Фессалия. Крит. // История древнего мира. Т.2. История Древней Греции. Ч.І/ под ред. С. И. Ковалева. М.: [б.и.], 1937. С. 206-255.

Schmidt R. Sparta. Beotia. Fessalia, Krit (Sparta. Boeotia. Thessaly. Crete) // Istoria drevnego mira. Vol.2. Istoria drevnei Grecii. Vol.I / ed by S.I. Kovalev. Moscow, 1937. P. 206-255. (In Russian).

2. Curnow T. The oracles of the Ancient World. London, 2003. 180 p.

3. Dakaris S. Dodona. Athens, 1996. $48 \mathrm{p}$.

4. Gwatkin W. E. Dodona, Odysseus and Aeneas // The Classical Journal. Vol.57. №3. P. 97-102.

5. Hammond N. G. L. Epirus. Oxford, 1967. 847 p.

6. Landscape Archeology in Southern Epirus / ed.J.Wiseman and K. Zachos // Hesperia Supplementum 32. 2003. 283 p

7. Mustakis N. Heiligtumer als politische Zentren. Munchen, 2006. $237 \mathrm{~s}$.

8. Oberhummer E. Akarnanien, Ambrakia, Amphilochien und Leukas in Altertum. Munchen, 1887. $234 \mathrm{~s}$.

9. Schmidt H. Epeirotica. Marburg, 1894. $114 \mathrm{~s}$.

10. Treidler H. Epirus in Altertum. Studien zur historischen Topographie. Leipzig, 1917. $176 \mathrm{~s}$. 
11. Wandenberg A. Das Geheimnis der Orakel. Munchen, 1979. 352 s.

12. Wordsworth C. La Grece pittoresque et historique. Trad. Par E.Regnault. Paris, 1841. 356 p.

\section{Информация об авторе}

Казаров Саркис Суренович - доктор исторических наук, профессор кафедры археологии и истории Древнего мира Южного федерального университета (Ростов-на-Дону) / ser-kazarov@yandex.ru

\section{Information about the author}

Kazarov Sarkis - Doctor of History, Professor, Chair of Archaeology and Ancient History of Institute of History and International Relations, Southern Federal University (Rostov-on-Don) / ser-kazarov@yandex.ru 